\title{
Novel Diversity Identified in a Wild Apple Population from the Kyrgyz Republic
}

\author{
Gayle M. Volk ${ }^{1}$, Christopher M. Richards, Adam D. Henk, and \\ Ann Reilley \\ National Center for Genetic Resources Preservation, U.S. Department of \\ Agriculture, 1111 South Mason Street, Fort Collins, CO 80521
}

\author{
Diane D. Miller \\ Department of Horticulture and Crop Science, The Ohio State University, \\ Wooster, OH 44691
}

\section{Philip L. Forsline}

Plant Genetic Resources Unit, U.S. Department of Agriculture, Geneva, NY 14456-0462

Additional index words. apple, Malus, simple sequence repeat, genetic diversity

\begin{abstract}
The genetic diversity of a wild Malus population collected in the Kyrgyz Republic was compared with seedlings of Malus sieversii collected in Kazakhstan. Based on microsatellite marker results, we conclude that the population of 49 individuals collected in the Kyrgyz Republic includes private alleles and this population is assigned to a common genetic lineage with $M$. sieversii individuals found in the Karatau Mountain range of Kazakhstan. We recommend that a subset of these individuals be included in the National Plant Germplasm System Malus collection so they may be made available to breeders, physiologists, and other scientists for further examination.
\end{abstract}

The wild apple species Malus sieversii (Ledeb.) M. Roem. is native to xeric regions and high mountain ranges of Kazakhstan, the Kyrgyz Republic, China, Tajikistan, Uzbekistan, and Turkmenistan (Yan et al., 2008). With a wide range of edible phenotypes observed in its natural habitat, $M$. sieversii is believed to be a primary progenitor species of the cultivated apple (M. × domestica) (Harris et al., 2002; Luby et al., 2001; Watkins, 1995). Yan et al. (2008) suggested that the apple forests of Central Asia represent a derived form of $M$. sieversii, and the forests in the Xinyuan (Xinjiang) province in China represent a more primitive form.

Received for publication 13 Nov. 2008. Accepted for publication 13 Jan. 2009.

We acknowledge the support of Winrock International Central Asia Farmer-to-Farmer program funded by the U.S. Agency for International Development. This project was partially supported by the National Research Initiative of the USDA Cooperative State Research, Education and Extension Service (grant no. 2005-00751). The collection trip to the Kyrgyz Republic was supported by the Winrock International Central Asia Farmer-to-Farmer program funded by the U.S. Agency for International Development.

We thank Angela Baldo for reviewing the manuscript before submission.

Any mention of trade names or commercial products in this article is solely for the purpose of providing speciffic information and does not imply recommendation or endorsement by the U.S. Department of Agriculture.

${ }^{1}$ To whom reprint requests should be addressed; e-mail Gayle.Volk@ars.usda.gov.
In some texts, Malus kirghisorum is considered a unique Malus species, closely related to M. sieversii (Dzhangaliev, 2003). Fruits of both $M$. kirghisorum and $M$. sieversii are diverse in size, form, color, and flavor, ranging from sour-sweet to acid to bitter and astringent and have $10 \%$ to $12 \%$ sugar (Dzhangaliev et al., 2003). The habitats of $M$. sieversii and $M$. kirghisorum are overlapping and heterogenetic populations of these species exist in areas of close contact. Malus sieversii is found in many habitats, whereas M. kirghisorum is reported to be found specifically in rich, moist soils of northern slopes between elevations of 1200 and $1800 \mathrm{~m}$. Malus kirghisorum is believed to have become more localized during periods of glaciation, whereas the more adaptable $M$. sieversii became more widely distributed (Dzhangaliev, 2003). Malus kirghisorum is considered mesophyllous and found adjacent to relict walnut, aspen, hawthorn, and maple forests (Dzhangaliev, 2003).

The USDA has sponsored four collection trips to Kazakhstan to collect Malus sieversii germplasm (Forsline et al., 2003; Hokanson et al., 1997). The genetic diversity of seedling apple trees originating from seeds collected in Kazakhstan has been previously described (Richards et al., 2009). Nine hundred fortynine $M$. sieversii seedling individuals representing 88 half-sib families collected in the forests of Kazakhstan were compared using seven unlinked microsatellite markers (Richards et al., 2009). Classification of individuals into four clusters based on Bayes- ian assignment tests illustrated that genetic differentiation aligned with regional location. Individuals from the eastern Kazakhstan collection Sites 4, 5, and 9 (and half of the individuals from Sites 3 and 10) were predominantly localized to Cluster 1 . Cluster 2 included individuals from across southern Kazakhstan, including Sites 3, 6, 10, 11, and 12. Sites 10, 11, and 12 also included individuals that were assigned to Clusters 3 and 4 (Richards et al., 2009).

In this work, we compared the genetic diversity of the $M$. sieversii forests of Kazakhstan with a set of Malus seedlings resulting from seeds collected in the forests of the Kyrgyz Republic. We identified genotypes based on neutral allele variation that could complement the USDA-National Plant Germplasm System germplasm collections of $M$. sieversii.

\section{Materials and Methods}

Plant materials. In 2005, a collection expedition led by Dr. Diane Miller to the Kyrgyz Republic (sponsored by Winrock International Central Asia Farmer-to-Farmer program funded by the U.S. Agency for International Development) sought to identify new germplasm that represented novel diversity that could be useful to apple-breeding programs in the midwestern United States. This collection trip focused on the forests in the Arslanbob region (lat. 41.333, long. 72.933, elevation $1446 \mathrm{~m}$ ) of the Kyrgyz Republic and resulted in the collection of 2500 seeds from a highly diverse site that was $25 \mathrm{~km}^{2}$ and contained hundreds of wild apple trees (Fig. 1). The collection site was characterized as predominantly wild Juglans with a lesser amount of wild Malus. The wild Malus was classified as Malus kirghisorum based on elevation and political boundary definitions of species delineations. All the Malus seeds from the Kyrgyz Republic were planted in Carrollton, $\mathrm{OH}$, for evaluation purposes. Leaf samples from 50 randomly sampled seedlings were collected and sent to the USDA-ARS National Center for Genetic Resources Preservation in Ft. Collins, $\mathrm{CO}$, for genotyping.

Molecular genotyping. Genomic DNA from duplicate leaf samples from $50 \mathrm{M}$. sieversii trees was extracted using DNeasy plant kits (Qiagen, Valencia, CA) as previously reported (Volk et al., 2005). Malus microsatellites (simple sequence repeat) were amplified using unlinked primers (GD12, GD15, GD96, GD100, GD142, GD147, GD162) (Hemmat et al., 2003; Hokanson et al., 1998). Standard cultivar controls were Golden Delicious, Rome Beauty Law, and Cox Orange Pippin. Polymerase chain amplifications were performed as previously described (Volk et al., 2005). Unlabeled reverse primers were purchased from IDT (Coralville, IA) and forward primers, labeled with either IRD 700 or IRD 800, were obtained from MWG-Biotech (High Point, NC). Amplified products were multiplexed on a DNA sequencer (model 


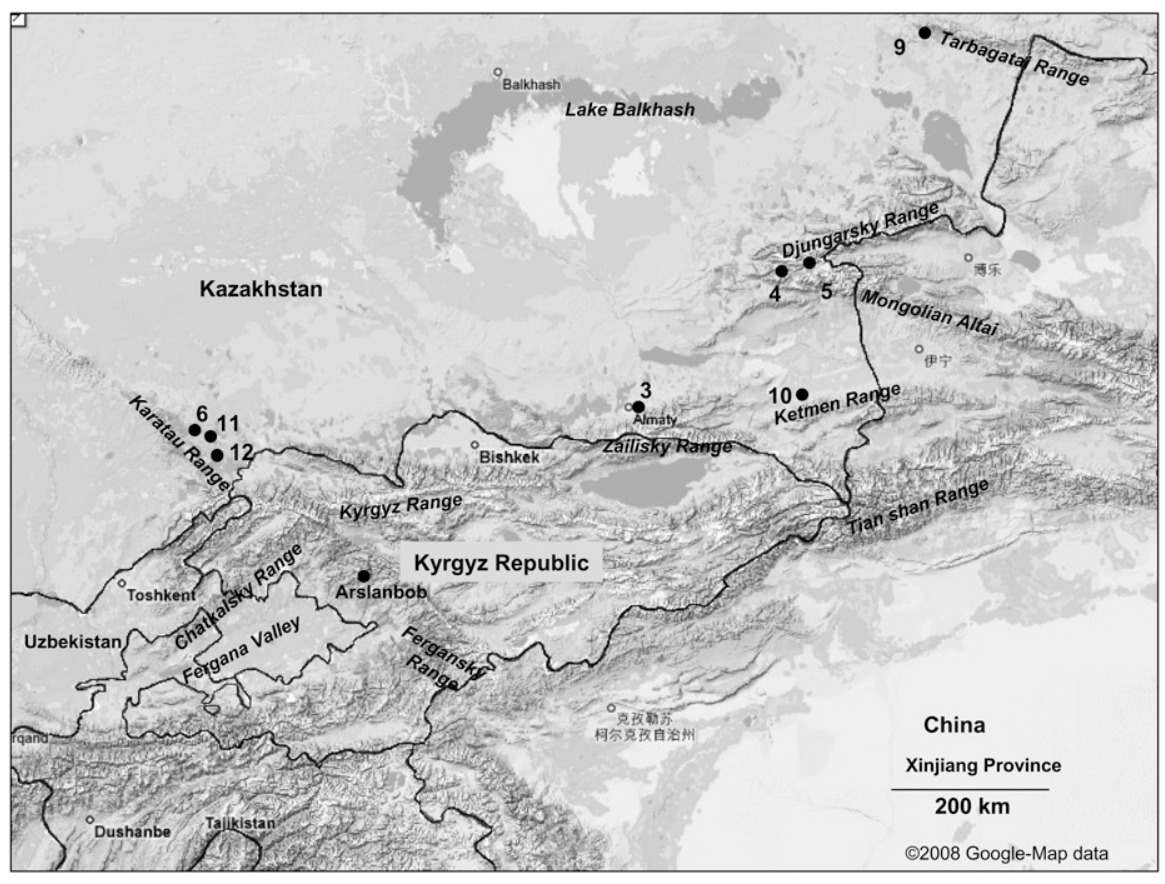

Fig. 1. Map of Central Asia showing eight collection sites for Malus sieversii in Kazakhstan and the Arslanbob locality of the Kyrgyz Republic. Dominant mountain ranges are labeled.

Table 1. Genetic diversity for each of the numbered eight Kazakhstan collection sites and the Kyrgyz Republic collection site $(\mathrm{K})$ measured by effective heterozygosity $(\mathrm{He})$, observed heterozygosity (Ho), allelic richness, and the number of private alleles based on microsatellite data.

\begin{tabular}{rrcccc}
\hline Site & $\mathrm{n}$ & $\begin{array}{c}\text { Effective } \\
\text { heterozygosity }\end{array}$ & $\begin{array}{c}\text { Observed } \\
\text { heterozygosity }\end{array}$ & $\begin{array}{c}\text { Allelic } \\
\text { richness }\end{array}$ & $\begin{array}{r}\text { Private } \\
\text { alleles }\end{array}$ \\
\hline 3 & 24 & 0.66 & 0.67 & 6.94 & 2 \\
4 & 91 & 0.61 & 0.62 & 5.88 & 0 \\
5 & 146 & 0.73 & 0.74 & 7.42 & 2 \\
6 & 167 & 0.73 & 0.69 & 6.89 & 5 \\
9 & 263 & 0.70 & 0.68 & 6.38 & 3 \\
10 & 53 & 0.69 & 0.72 & 6.55 & 0 \\
11 & 117 & 0.76 & 0.71 & 7.42 & 4 \\
12 & 88 & 0.71 & 0.70 & 6.30 & 5 \\
K & 49 & 0.72 & 0.72 & 6.55 & 6 \\
\hline
\end{tabular}

${ }^{\mathrm{z}}$ Allelic richness measurements were normalized based on minimum sample size of 32 diploid individuals.

4200; LI-COR Inc., Lincoln, NE) using denatured acrylamide gels (Volk et al., 2005). Digital images were manually interpreted using LI-COR Saga ${ }^{\mathrm{TM}}$ Generation 2 software. Individuals were included in the analyses when they had missing data for no more than one marker.

Molecular data analysis. The genetic diversity of $M$. sieversii genotypes collected from Kazakhstan has been previously described using the same set of microsatellite markers (Richards et al., 2009). The current analyses sought to compare the differentiation and diversity of the samples from the Kyrgyz Republic in the context of the 949 accessions assayed from eight locations in Kazakhstan (Fig. 1). Genotypic data were analyzed using the software package GDA (Lewis and Zaykin, 2001) and FSTAT (Goudet, 1995). Allelic richness measurements were normalized using the method of El Mousadik and Petit (1996).

In addition to estimating population genetic parameters from a priori-defined collection sites, we also used a nonhierarchical genotypic clustering method (Pritchard et al., 2000), which allows genotypes to form clusters without prior information about sampling structure. This method is useful for estimating regional patterns of differentiation that may otherwise go unrecognized. This Bayesian clustering was performed using the genotypes obtained for all 49 Kyrgyz Republic individuals (one genotype was discarded as a result of unacceptably high levels of missing data) as well as a combined data set that included 949 M. sieversii samples from Kazakhstan. Allelic richness statistics were calculated among genetic clusters. We graphically displayed the relative differentiation among collection sites and genetic clusters by using a minimum spanning network (Excoffier et al., 2005).

\section{Results and Discussion}

An evaluation of the genetic diversity of Malus seedling trees from the Kyrgyz Republic is most informative when placed in the context of the known diversity of the wild apple species $M$. sieversii in neighboring
Kazakhstan. The Kyrgyz Republic site near Arslanbob is separated by $\approx 200 \mathrm{~km}$ from the nearest Kazakhstan sites by the rugged Karatau and Kyrgyz mountain ranges.

The sample size per collection site ranged from 24 individuals in Site 3 to 263 individuals in Site 9 (Table 1). Despite the discrepancy in population sizes, the effective heterozygosity, observed heterozygosity, and allelic richness were similar across the collection sites. A total of 106 alleles were amplified using seven markers in the seedlings from the Kyrgyz Republic site. In comparison, a total of 103 alleles were amplified in the set of 949 seedlings from the eight Kazakhstan sites (Richards et al., 2009). The set of individuals from the Kyrgyz Republic has six private alleles. These alleles were each found in more than one individual originating from the Kyrgyz Republic but not identified in any of the seedlings originating in Kazakhstan (Table 1).

Genotypes of the 949 Kazakhstan seedlings and the 49 Kyrgyz Republic seedlings were included in cluster analyses to identify which, if any, of the four Kazakhstan clusters shared lineages with the Kyrgyz Republic seedlings. These assignment tests were inconclusive because the 49 individuals were not stable across replicate Markov chain Monte Carlo runs. We determined that the optimal number of clusters (k) based on posterior likelihood increased from four to five when the 49 Kyrgyz Republic individuals were included in the data set. The 49 Kyrgyz Republic individuals shared a common lineage that comprised the fifth cluster (Table 2).

Measures of genetic differentiation across the five clusters revealed similar levels of effective heterozygosity, observed heterozygosity, and allelic richness (Table 3 ). When analyzed by cluster, the number of private alleles ranged from four private alleles in Clusters 3 and 4 to nine private alleles in Cluster 1 and five private alleles in Cluster 5 (Kyrgyz Republic) (Table 3).

Network diagrams were developed to illustrate the relationships among the individuals in the nine sites or among the five clusters (Fig. 2). The site network diagram demonstrates the relationship among the north and central eastern Kazakhstan Sites 9,4 , and 5 with Site 3 more closely aligned with Site 5 than the other sites. Site 10 is centrally positioned in the network, with

Table 2. Site representation in each of the five clusters.

\begin{tabular}{llllll}
\hline & \multicolumn{5}{c}{ Cluster } \\
\cline { 2 - 6 } Site & \multicolumn{1}{c}{1} & \multicolumn{1}{c}{2} & \multicolumn{1}{c}{3} & \multicolumn{1}{c}{4} & \multicolumn{1}{c}{5} \\
\hline 3 & 0.02 & 0.05 & 0 & 0 & 0 \\
4 & 0.16 & 0.02 & 0 & 0 & 0 \\
5 & 0.24 & 0.04 & 0.02 & 0 & 0 \\
6 & 0.06 & 0.52 & 0 & 0.03 & 0 \\
9 & 0.45 & 0.02 & 0.03 & 0 & 0 \\
10 & 0.05 & 0.08 & 0.07 & 0 & 0 \\
11 & 0.02 & 0.21 & 0.28 & 0.76 & 0 \\
12 & 0.01 & 0.08 & 0.60 & 0.21 & 0 \\
K & 0 & 0 & 0 & 0 & 1.00 \\
Total & 1.00 & 1.00 & 1.00 & 1.00 & 1.00 \\
\hline
\end{tabular}


Table 3. Genetic diversity for each of five clusters measured by effective heterozygosity (He), observed heterozygosity (Ho), allelic richness, and the number of private alleles based on microsatellite data. ${ }^{2}$

\begin{tabular}{lccccc}
\hline Cluster & $\mathrm{n}$ & $\begin{array}{c}\text { Effective } \\
\text { heterozygosity }\end{array}$ & $\begin{array}{c}\text { Observed } \\
\text { heterozygosity }\end{array}$ & $\begin{array}{c}\text { Allelic } \\
\text { richness }\end{array}$ & $\begin{array}{c}\text { Private } \\
\text { alleles }\end{array}$ \\
\hline 1 & 571 & 0.71 & 0.69 & 7.83 & 9 \\
2 & 262 & 0.74 & 0.7 & 7.43 & 6 \\
3 & 93 & 0.67 & 0.71 & 7.97 & 4 \\
4 & 35 & 0.64 & 0.65 & 8.79 & 4 \\
5 & 49 & 0.72 & 0.72 & 6.75 & 6 \\
\hline
\end{tabular}

${ }^{\mathrm{z}}$ Allelic richness measurements were normalized based on minimum sample size of 32 diploid individuals.

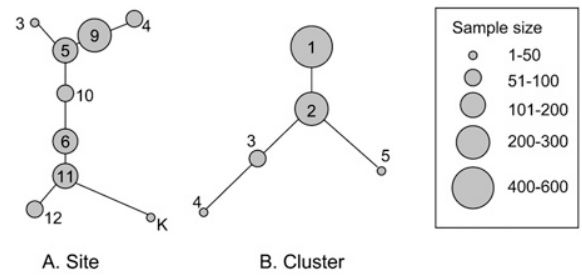

- Fst $=0.05$

Fig. 2. Network diagrams illustrate the genetic relationships among (A) sites and (B) clusters of wild apple populations in Kazakhstan and in the Kyrgyz Republic.

Sites 6, 11, and 12 grouping together. The Kyrgyz Republic site (labeled K) shares most similar allelic composition with Site 11, one of the Kazakhstan sites that is south and centrally located.

The relationship of the clusters reveals that Cluster 1 representing the eastern Kazakhstan sites and Cluster 2, representing many individuals in the southern Kazakhstan Sites 6, 11, 12 , and 10 , contain most of the $M$. sieversii individuals genotyped. Clusters 3 (primarily Sites 11 and 12) and 4 (primarily Sites 11 and 12) show signs of differentiation from Cluster 2 , a widespread and common genetic lineage found in Kazakhstan. Cluster 5, comprised of the Kyrgyz Republic individuals, exhibits an alternative differentiation from the Cluster 2 set of individuals (Fig. 2B). This may have resulted in some novelty resulting from colonization of individuals from a common source lineage. As a result of the rugged mountainous terrain, subsequent gene flow among the Kyrgyz Republic individuals from the Arslanbob region could be limited.

Some taxonomists have described the apple populations within the Kyrgyz Republic to represent a novel Malus species, Malus kirghisorum. Despite the local levels of differentiation observed across the southern tier of Kazakhstan and into the Kyrgyz Republic, the diversity does not support the consideration of the Kyrgyz Republic individuals as a unique and independent species. Malus kirghisorum and $M$. sieversii are not itate and hybrids between the species are reported to have particularly diverse phenotypes (Dzhangaliev, 2003). In addition, the lack of specific phenotypic traits distinguishing the species is another example supporting the lack of species differentiation between $M$. kirghisorum and M. sieversii.

In conclusion, we have identified novel forms of diversity within the $M$. sieversii individuals that have been recently collected in the Kyrgyz Republic. Because these individuals comprise an additional cluster, they likely share a common genetic lineage that may provide novel and useful phenotypic traits. We have recommended that 12 of the Kyrgyz individuals be included in the National Plant Germplasm System Malus collection so they may be made available to breeders, physiologists, and other scientists for further examination.

\section{Literature Cited}

Dzhangaliev, A.D. 2003. The wild apple tree of Kazakhstan. Hort. Rev. (Amer. Soc. Hort. Sci.) 29:63-303.

Dzhangaliev, A.D., T.N. Salova, and P.M. Turekhanova. 2003. The wild fruit and nut plants of Kazakhstan. Hort. Rev. (Amer. Soc. Hort. Sci.) 29:305-371.

El Mousadik, A. and R.H. Petit. 1996. High level of genetic differentiation for allelic richness among populations of the argan tree [Argania spinosa (L.) Skeels] endemic of Morocco. Theor. Appl. Genet. 92:832-839.

Excoffier, L.G.L. and S. Schneider. 2005. Arlequin ver. 3.0: An integrated software package for population genetics data analysis. Evol. Bioinreproductively isolated, because they cohab- form. Online 1:47-50. <http://lgb.unige.ch/ arlequin/>.

Forsline, P.L., H.S. Aldwinckle, E.E. Dickson, and S.C. Hokanson. 2003. Collection, maintenance, characterization, and utilization of wild apples from central Asia. Hort. Rev. (Amer. Soc. Hort. Sci.) 29:1-61.

Goudet, J. 1995. FSTAT, a program for IBM PC compatibles to calculate Weir and Cockerham's (1984) estimators of F-statistics. J. Hered. 86:485-486.

Harris, S.A., J.P. Robinson, and B.E. Juniper. 2002. Genetic clues to the origin of the apple. Trends Genet. 18:426-430.

Hemmat, M., N.F. Weeden, and S.K. Brown. 2003. Mapping and evaluation of Malus $\times$ domestica microsatellites in apple and pear. J. Amer. Soc. Hort. Sci. 128:515-520

Hokanson, S.C., J.R. McFerson, P.L. Forsline, W.F. Lamboy, A.D. Djangaliev, and H.S. Aldwinckle. 1997. Collecting and managing wild Malus germplasm in its center of diversity. HortScience 32:173-176.

Hokanson, S.C., A.K. Szewc-McFadden, W.F. Lamboy, and J.R. McFerson. 1998. Microsatellite (SSR) markers reveal genetic identities, genetic diversity and relationships in a Malus $\times$ domestica borkh. core collection. Theor. Appl. Genet. 97:671-683.

Lewis, P.O. and D. Zaykin. 2001. GDA user's manual. Department of Ecology and Evolutionary Biology, University of Connecticut, 27 July 2004. <http://lewis.eeb.uconn.edu/lewishome>

Luby, J., P. Forsline, H. Aldwinckle, V. Bus, and M. Giebel. 2001. Silk road apples-Collection, evaluation, and utilization of Malus sieversi from Central Asia. HortScience 36:225-231.

Pritchard, J.K., M. Stephens, and P. Donnelly. 2000. Inference of population structure using multilocus genotype data. Genetics 155:945-959.

Richards, C.M., G.M. Volk, A.A. Reilley, A.D. Henk, D.R. Lockwood, P.A. Reeves, and P.L. Forsline. 2009. Genetic diversity and population structure in Malus sieversii, a wild progenitor species of domesticated apple. Tree Genet. Genomes. <http://www.springerlink.com/content/ 48741v0122104gu1/fulltext.pdf>

Volk, G.M., C.M. Richards, A.A. Reilley, A.D Henk, P.L. Forsline, and H.S. Aldwinckle. 2005. Ex situ conservation of vegetativelypropagated species: Development of a seedbased core collection for Malus sieversii. J. Amer. Soc. Hort. Sci. 130:203-210.

Watkins, R. (1995). Apple and pear, p. 418-422. In: Smartt, J. and N.W. Simmonds (eds.). Evolution of crop plants. Longman Scientific and Technical, Essex, UK.

Yan, G.R., H. Long, W.Q. Song, and R.Y. Chen. 2008. Genetic polymorphism of Malus sieversii populations in Xinjiang, China. Genet. Resources Crop Evol. 55:171-181. 